\title{
Educação e tecnologias digitais em tempos de pandemia: uma experiência, muitos desafios
}

Education and digital technologies in times of pandemic: one experience, many challenges

Educación y tecnologías digitales en tiempos de pandemia: una experiencia, muchos desafíos

Luciana Mara Monti Fonseca ${ }^{1}$ (D) https://orcid.org/0000-0002-5831-8789

Adriana Moraes Leite ${ }^{1}$ (D) https://orcid.org/0000-0001-8327-8718

Danielle Monteiro Vilela ${ }^{1}$ (D) https://orcid.org/0000-0003-1988-3133

Débora Falleiros de Mello ${ }^{1}$ (D) https://orcid.org/0000-0001-5359-9780

Lucila Castanheira Nascimento ${ }^{1}$ (D) https://orcid.org/0000-0002-7900-7111

Maria Cândida Carvalho Furtado ${ }^{1}$ (D) https://orcid.org/0000-0001-7942-4110

Marta Angélica lossi Silva ${ }^{1}$ (D) https://orcid.org/0000-0002-9967-8158

Regina Aparecida Garcia de Lima $^{1}$ (D) https://orcid.org/0000-0002-0611-5621

\section{Resumo}

Objetivou-se relatar e discutir o desenvolvimento do processo de ensino-aprendizagem sobre a saúde da criança hospitalizada com graduandos em enfermagem durante a pandemia da COVID-19. Para implementar 0 ensino remoto emergencial, percorreram-se as etapas: planejamento da disciplina mediante elaboração de plano de atividades; escolha e preparação do método, definição das estratégias de ensino e atividades; inserção da disciplina na plataforma e-Disciplinas e das atividades síncronas e assíncronas e disponibilização dos materiais e ferramentas; aplicação das atividades teóricas e avaliação da disciplina. No ensino remoto, destacam-se aspectos relevantes aprendidos conjuntamente: localização do professor na "sala de aula" virtual, imagem na tela, mediação das discussões relatada pelos professores como sair do lugar comum ("frente da sala" e ir para o "lado a lado"), potencialidade para realizar intervenções individuais e grupais, auxílio para construção conjunta do conhecimento e proatividade no processo ensino-aprendizagem, com vistas à participação ativa do sujeito que aprende.

\section{Abstract}

The aim was to report on and discuss the development of the teaching-learning process about the health of hospitalized children involving undergraduate nursing students during COVID-19. To implement emergency remote teaching, the following steps were completed: planning of the subject by elaborating a detailed activity plan; choice and preparation of the method, teaching strategies and activities; inclusion of the subject, synchronous and asynchronous activities on the e-Disciplinas platform and release of the material and tools; application of the theoretical activities and assessment. In the remote teaching, relevant aspects learned together stand out: location of the teacher in the virtual "classroom", image on screen, mediation of discussions reported by the teachers as out-of-the-box thinking (from "in front of the class" to "side by side"), potential for individual and group interventions, help for joint knowledge construction and greater proactiveness in the teaching-learning process, with a view to the learning subject's active participation.

\section{Resumen}

La finalidad fue relatar y discutir el proceso de enseñanza-aprendizaje sobre la salud del niño hospitalizado con alumnos de pregrado en enfermería durante COVID-19. Para implementar enseñanza remota de emergencia, se realizaron las etapas: planificación de la asignatura mediante un plan detallado de actividades; elección y preparación del método, estrategias de enseñanza y actividades; inserción de la asignatura, actividades síncronas y asíncronas en la plataforma e-Disciplinas y disposición de los materiales y herramientas; aplicación de actividades teóricas y evaluación. En la enseñanza remota, se destacan aspectos relevantes aprendidos conjuntamente: posición del profesor en la "clase" virtual, imagen en la pantalla (profesor y estudiantes), mediación de discusiones relatada por los profesores como estar fuera de la caja ("delante de la clase" hasta "junto al otro"), potencial para intervenciones individuales y en grupo, ayuda para construcción conjunta del conocimiento y mayor proactividad en la enseñanza-aprendizaje, visando a la participación activa del alumno.

\section{Como citar:}

Fonseca LM, Leite AM, Vilela DM, Mello DF, Nascimento LC, Furtado MC, et al. Educação e tecnologias digitais em tempos de pandemia: uma experiência, muitos desafios. Rev Soc Bras Enferm Ped. 2020;20(Especial COVID-19):91-101.

\section{Descritores}

Enfermagem pediátrica; Enfermagem neonatal; Educação em enfermagem; Tecnologia educacional; Pandemia

\section{Keywords}

Pediatric nursing; Neonatal Nursing; Education, Nursing; Educational Technology; Pandemics

\section{Descriptores}

Enfermería pediátrica; Enfermería

Neonatal; Educación en Enfermería; Tecnología Educacional, Pandemias

${ }^{1}$ Escola de Enfermagem de Ribeirão Preto, Universidade de São Paulo, Ribeirão Preto, SP, Brasil.

Conflitos de interesse: nada a declarar.

Submetido: 17 de Julho de 2020 | Aceito: 18 de Setembro de 2020

Autor correspondente: Luciana Mara Monti Fonseca | E-mail: lumonti@eerp.usp.br

DOI: http://dx.doi.org/10.31508/1676-3793202000000130 


\section{Introdução}

A educação digital apresenta-se como um campo em evolução e tem sido identificada como um dos possíveis meios para enfrentar crescentes desafios. Sua utilização mostra-se crescente em todos os níveis de formação e desenvolvimento contínuo de profissionais de saúde, com impacto potencialmente grande e favorável na qualidade da atenção ao paciente. ${ }^{(1)}$

Neste contexto, os componentes digitais podem apoiar a educação no ensino superior e nos processos assistenciais direcionados a crianças e adolescentes, com vistas a melhorar o cuidado de enfermagem prestado. Assim, o uso das tecnologias digitais inovadoras imbricadas em metodologias ativas de aprendizagem pode otimizar a formação em enfermagem pediátrica e neonatal. ${ }^{(2)}$ A opção por utilizar tecnologias digitais no processo ensino-aprendizagem da saúde da criança, especialmente na última década, justifica-se pela presença majoritária de estudantes identificados como nativos digitais, ${ }^{(3,4)}$ ou seja, que apresentam características e habilidades para aprender mais naturalmente no mundo digital.

Para essa geração, o uso das tecnologias digitais como games, e-mails, internet, dispositivos, aplicativos móveis e mensagens instantâneas é parte inerente do cotidiano, pois já estão familiarizados com informações disparadas em formato de imagens, símbolos e códigos em fluxo alucinante e possuem pensamento e raciocínio em forma rizoma. São também capazes de ler hipertextos, não lineares e aparentemente alternados a cada clique, diferentemente dos denominados imigrantes digitais, que apenas na vida adulta aprenderam a manusear essas tecnologias. ${ }^{(3,4)}$

Nesta era digital e globalizada, em que os sotaques dos imigrantes digitais são cada vez menos evidentes, fica ainda mais clara e pertinente a proposta de um saber digital, que independa da idade ou geração. ${ }^{(4)}$ Além disso, em momentos de pandemia, tornam-se prementes reorganizações e readaptações.

Na situação da pandemia da COVID-19 (Coronavirus Disease 2019), causada pelo SARS-CoV-2 (Severe Acute Respiratory Syndrome Coronavirus 2), ${ }^{(5)}$ foram recomendadas ${ }^{(6-7)}$ medidas de distanciamento social, vigilância dos casos, estímulo à higiene das mãos e à etiqueta respiratória, além do uso de máscaras faciais. Essas medidas foram implementadas de modo gra- dual e distinto nos diferentes países e, mesmo dentro deles, com maior ou menor intensidade. Os resultados dessas ações, provavelmente, dependiam de aspectos socioeconômicos, culturais, de características dos sistemas políticos e de saúde, bem como dos procedimentos operacionais adotados para implementá-las. ${ }^{(8)}$

No âmbito do ensino universitário, a partir de março de 2020 foi recomendado o "ensino remoto emergencial", denominação que vem sendo utilizada mundialmente para o ensino on-line. ${ }^{(9)}$ Assim, diante desta recomendação, objetiva-se neste estudo relatar e discutir o desenvolvimento do processo ensino-aprendizagem sobre a saúde da criança hospitalizada com graduandos em enfermagem durante a pandemia de COVID-19.

\section{Métodos}

Este relato de experiência apresenta o desenvolvimento de uma disciplina de graduação sobre a saúde da criança hospitalizada, a qual integra o Curso de Enfermagem de uma instituição pública de estado de São Paulo - Brasil. A referida disciplina foi oferecida remotamente durante o período de distanciamento social para controle da pandemia da COVID-19.

\section{Ensino de Enfermagem Neonatal e Pediátrica: relato de uma disciplina de graduação}

A disciplina tem carga horária total de 120 horas e é regularmente ministrada duas vezes no semestre, para uma média de 25 alunos por turma. Antes da pandemia, na modalidade presencial, já estavam previstas duas atividades on-line (chats educacionais), com quatro horas. Os conteúdos teóricos somariam $40 \%$ do total de horas e o restante seria distribuído em atividades teórico-práticas, desenvolvidas na unidade de ensino - em laboratórios de simulação realística e de habilidades - e, no hospital, nas Unidades de Cuidado Intermediário Neonatal, de Alojamento Conjunto e de Internação Pediátrica.

No entanto, após as medidas de distanciamento social e consequente reorganização das atividades acadêmicas, têm sido promovidas, principalmente, 
atividades teóricas. Uma pequena parte das atividades teórico-práticas foi redesenhada para a plataforma virtual de aprendizagem da USP, denominada e-Disciplinas, e para o Google Meet ${ }^{\circledR}$, com auxílio de ferramentas educativas e métodos ativos diferenciados, voltados aos nativos digitais.

Para a descrição e discussão deste relato acerca do processo de ensino-aprendizagem sobre a saúde da criança hospitalizada desenvolvido de forma não presencial com graduandos de enfermagem durante a pandemia da COVID-19, foram percorridas as seguintes etapas:

\section{Revisão do planejamento inicial da disciplina}

A experiência relatada foi vivenciada na Universidade de São Paulo, campus de Ribeirão Preto, especificamente na (Escola de Enfermagem de Ribeirão Preto (EERP-USP), com estudantes do Curso de Bacharelado e Licenciatura em Enfermagem. O curso apresenta dez semestres como período ideal para conclusão. $\mathrm{Na}$ estrutura curricular, a disciplina é oferecida no penúltimo ano, sob o código ERM0309 - Cuidado Integral à Saúde da Criança e do Adolescente. Conta com sete docentes e foi oferecida duas vezes no primeiro semestre do 2020: turma 1, com 26 estudantes, e turma 2, 25 estudantes matriculados.

Por meio de reuniões on-line com professores da área, planejou-se a migração desta disciplina para o universo digital que trabalha a saúde da criança hospitalizada. Nesses encontros, construiu-se um plano detalhado, denominado "Programa e Cronograma da Disciplina". Este documento foi discutido e organizado cronologicamente descrevendo as 13 atividades teóricas e teórico-práticas não presencias da disciplina com suas respectivas temáticas, datas, duração, abordagens metodológicas e tecnologias digitais, de acordo com objetivos de aprendizagem e público-alvo: graduandos (jovens - nativos digitais).

As abordagens metodológicas precisam estar em consonância com os objetivos de aprendizagem pretendidos. Para potencializar a proatividade dos estudantes, são necessárias metodologias que proporcionem maior envolvimento em atividades gradativamente mais complexas, com tomadas de decisões e avaliação dos resultados, auxiliados por materiais relevantes. As metodologias ativas apresentam-se sob diferentes formatos neste mundo conectado e digital, podendo colaborar para o êxito do processo ensino-aprendizagem. ${ }^{(10)}$

Especificamente neste curso e disciplina, as metodologias ativas buscam estimular a aprendizagem significativa, a autonomia do estudante e sua participação ativa ao longo do processo de ser, estar e fazer enquanto sujeito do seu próprio aprender. Assim, inserir tecnologias digitais no processo ensino-aprendizagem requer reflexão acerca do papel dos professores e dos estudantes, bem como priorizar atividades embasadas nas metodologias ativas de aprendizagem e em avaliações formativas. A organização do espaço precisa ser repensada sob uma nova configuração, que potencialize as ações colaborativas. ${ }^{(11)}$

Repensar a organização deste novo espaço pedagógico para professores e alunos pelo componente eminentemente remoto, distante da configuração física de sala de aula, significou para os professores um desafio na construção criativa de um ambiente físico e emocional que proporcionasse sentido e apreensão de conhecimentos cognitivos. Além disso, tal ambiente foi planejado para reduzir os efeitos negativos do distanciamento social, potencializar a socialização e autonomia e estimular a expressão de emoções e sentimentos pelo momento ímpar de vida causado pela pandemia e pelo distanciamento. Havia, nisso tudo, a necessidade de o diferente traduzir as características dos alunos e transmitir proximidade, organização e segurança.

As reflexões sobre as abordagens pedagógicas, a forma como se ensina e a distância do aluno nesta forma de aprendizagem, mesmo se tratando de um nativo digital, já vinham sendo pauta nos diferentes espaços e gerando mudanças no processo de ensino-aprendizagem. Eram também corroboradas pelos argumentos de um estudioso ${ }^{(4)}$ que alerta, há quase uma década, para um dos maiores problemas nesta relação: a diferença entre as necessidades dos estudantes nativos digitais e as decisões educacionais tomadas pelos imigrantes digitais.

Apesar disso, há, atualmente, consenso sobre ser imprescindível o uso das diferentes tecnologias no processo de ensino e aprendizagem, visto que o professor percebe o mundo tecnológico e, com isso, busca novas possibilidades para otimizar a realidade do espaço educacional..$^{(12)}$ Nesse sentido, a inserção das tecnologias digitais pode minimizar a distância entre a forma como o professor ensina e o aluno aprende. 


\section{Escolha e preparação do método e das ferramentas}

Na seleção do método e das estratégias de ensino, destacaram-se as metodologias ativas, como a aula invertida. As tecnologias digitais educacionais de preferência foram as desenvolvidas pelo Grupo de Pesquisa em Enfermagem no Cuidado à Criança e ao Adolescente (GPECCA), vinculado à EERP-USP como produto de teses, dissertações e iniciações científicas e tecnológicas (sites, games, cartilhas, folders)..(2) Para além dessas, foram utilizados como materiais e ferramentas educativas hipertextos e textos em formato Portable Document Format (PDF), vídeos curtos gravados pelos próprios estudantes em anos anteriores da disciplina, áudios de auscultas pulmonar e cardíaca de curta duração, fotos e aulas em PDF e gravadas. As ferramentas prioritárias do e-disciplinas foram chat, fórum e exercícios.

Quando ingressa na sala de aula, o estudante, nativo digital, está tão profundamente imerso nos mais diferentes estímulos e movimentos (internet, televisão, games, smartphone, dentre outros), que percebe uma distância enorme do seu mundo 3D ou 4D em relação a este 1D, da sala de aula, em que se encontra. Por esse motivo, considera-se necessário proporcionar mais do que o único estímulo visual ou sonoro que vem da imagem da lousa ou da voz do professor, passível de ser acionado por um simples toque, para motivar os alunos. ${ }^{(13)}$

Com base neste reconhecimento, buscou-se, neste estudo, aumentar a motivação dos graduandos, não só mediante a escolha e preparação das melhores ferramentas/tecnologias digitais para a disciplina como por meio da promoção de discussões a respeito dos diversos multimeios disponíveis. Em seguida, optou-se por aqueles considerados mais adequados e de mais rápida navegação/contato, para que não fosse extrapolada a carga horária destinada para cada conteúdo.

As informações e os conhecimentos transmitidos devem ser cuidadosamente avaliados e selecionados com base na relevância que apresentam para o alcance de determinado propósito, para que não sejam apresentados de forma misturada, formando um verdadeiro labirinto para cada usuário. Também não devem ser disponibilizados em quantidade grande demais, que ele não consiga separar e classificar as informações. A qualidade do material é determinante para que a apren- dizagem aconteça de maneira autônoma e interativa, no sentido de motivar a interação do estudante com as tecnologias digitais, com os outros estudantes e com os professores. ${ }^{(14)}$ Ao se produzir tecnologias digitais para auxiliar no processo ensino-aprendizagem presencial ou a distância, é necessário que o material seja claro, bem definido e organizado em tópicos, mas, também, que o estudante consiga navegar por onde desejar. ${ }^{(15)}$

Assim, a escolha das tecnologias deu-se pela relevância para a temática, quantidade de tempo dispendida para navegação e aprendizagem em cada um dos módulos. Já a organização das ferramentas e tecnologias nos módulos seguiu uma ordem semelhante nos diferentes conteúdos.

Foram priorizados os multimeios de curta duração, por facilitarem o reconhecimento, a descrição e a comparação entre diferentes situações, e também pelo fato de apresentarem situações complexas de forma mais amigável. ${ }^{(16)}$ Destes, foram escolhidos vídeos educativos gravados pelos próprios estudantes de turmas anteriores, como já mencionado, e vídeos disponíveis na literatura, sempre de curta duração, com menos de um minuto cada (Figura 1).

Estudo mostra que aprender com os pares pode ser ainda mais significativo, pois há objetivos em comum a serem alcançados. ${ }^{(17)}$

O vídeo educativo potencializa a emoção, podendo ser um facilitador e motivador da aprendizagem dos estudantes. ${ }^{(18)} \mathrm{A}$ aprendizagem acontece mediante a ativação de redes neurais específicas, que respondem a estímulos ambientais, e os fatores relacionados às emoções influenciam fortemente nesse processo, devendo ser aproveitados pelos professores. ${ }^{(19)}$

As emoções positivas, entusiasmo, curiosidade, desafio e humor, por exemplo, impulsionam o estudante a aprender e melhoram a retenção de conhecimento. ${ }^{(18)}$ Por outro lado, emoções negativas como a raiva também são importantes no processo de ensino-aprendizagem, de modo que estratégias capazes de provocar emoções podem ser motivadoras da aprendizagem. ${ }^{(20)}$

Foram oferecidos quizzes aos estudantes, um deles contendo questões de concursos públicos para enfermeiros e outro implementado de multimeios, como áudios e vídeos, que permitiam respostas no próprio smartphone. Essas respostas e o desempenho da turma eram acompanhados em tempo real, na tela, pelo professor e estudantes. Os quizzes também foram uti- 


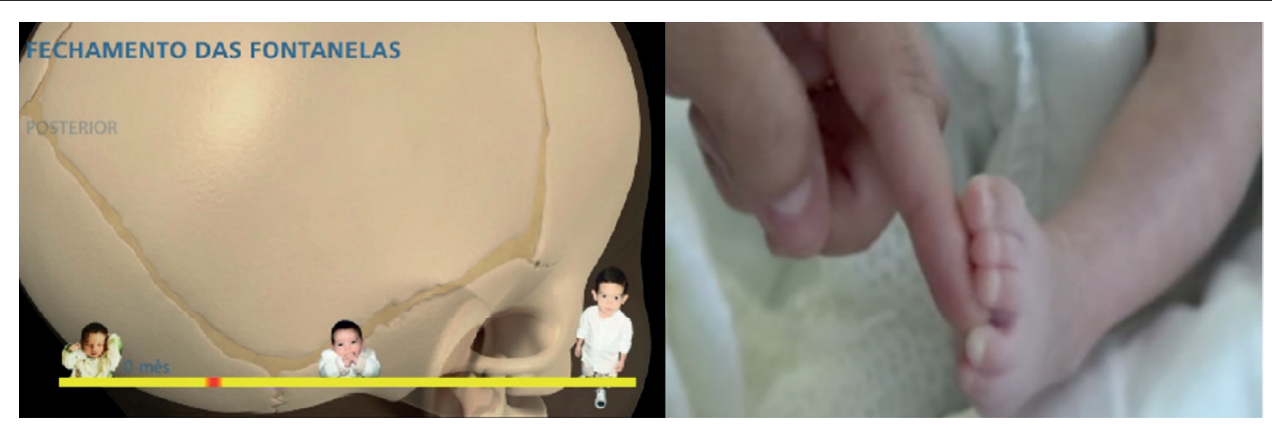

Figura 1. À esquerda, imagem capturada do vídeo do Homem Virtual da FM-USP e, à direita, imagem capturada do vídeo desenvolvido por estudantes que participaram da disciplina

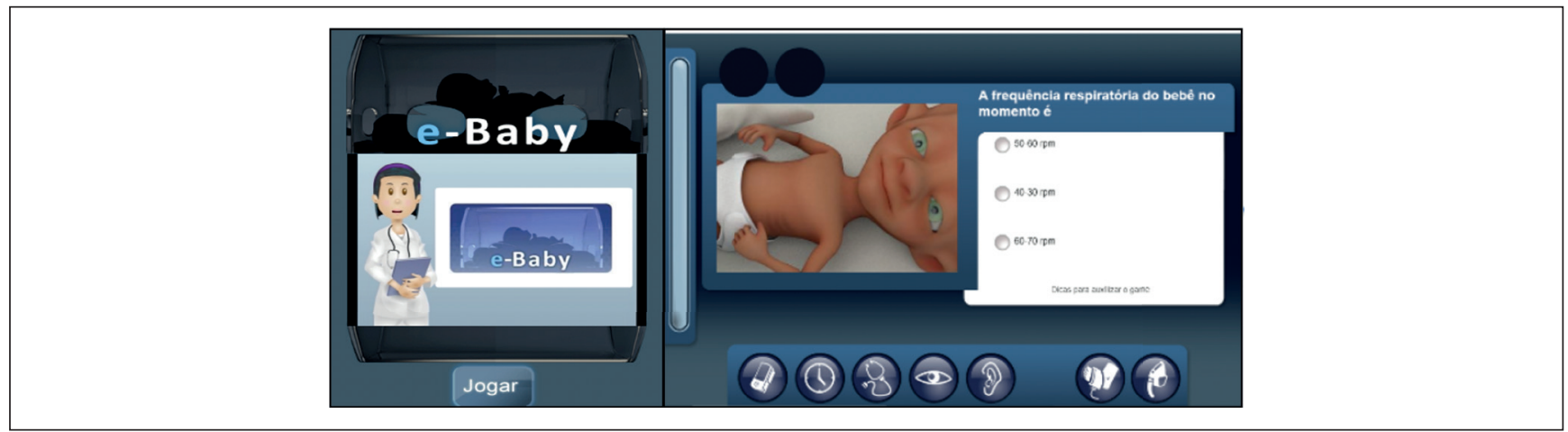

Figura 2. À esquerda, tela inicial do Serious game e-Baby e, à direita, uma das ações do jogo

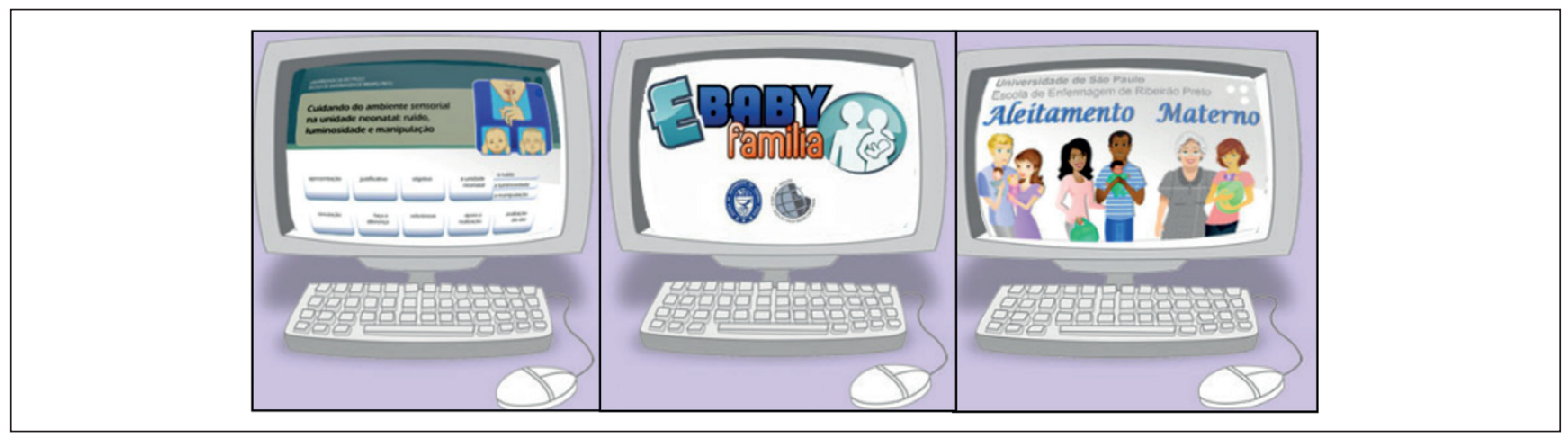

Figura 3. Serious games desenvolvidos pelo GPECCA

lizados após os encontros remotos, o que permitiu aos alunos a autoavaliação da aprendizagem e avaliação do processo de ensino pelo professor.

O quiz, se aplicado antes da aula, desperta o interesse do estudante sobre o tema e, para o mediador, permite uma avaliação diagnóstica da turma; durante e após a aula, oferece diversos benefícios: feedback para mediadores, motivação do estudante para o estudo, melhor retenção do conteúdo a longo prazo, identificação de eventuais lacunas no conhecimento, fixação reforçada da matéria, melhor organização do conheci- mento, entendimento ampliado a respeito da aplicação do conhecimento em diferentes contextos, estímulo à colaboração do aluno, aumento do senso de corresponsabilidade e reforço à confiança do estudante sobre o que sabe e sobre o que ainda precisa aprender.(21)

Neste estudo, foram utilizadas simulações virtuais no formato de serious games que podiam ser acessadas na própria plataforma do e-disciplinas e, também, via dispositivos móveis (Figuras 2 e 3).

Evidências apoiam a eficácia de serious games para melhoria dos conhecimentos, mudanças comporta- 
mentais e promoção de melhores resultados de saúde. (22) Jogos proporcionam aprendizado baseado na experiência, que motiva o estudante, além de alguns possuírem pontuação que exibem o progresso e desempenho do aluno, sendo essa característica atrativa aos nativos digitais. ${ }^{(23)}$

Outros benefícios importantes para a aprendizagem proporcionados pelos games incluem facilidade de acesso à informação desejada, fornecimento de respostas claras a dificuldades e problemas compatíveis com a realidade do aluno, síntese das melhores evidências científicas e possiblidade de jogar via smartphone ou outros dispositivos móveis. Isso não só gera no usuário um sentimento de segurança como o motiva a utilizar esses instrumentos. ${ }^{(24)}$

O uso de serious games para simulações virtuais deve ser precedido de algumas atividades. Trata-se de um prebriefing para esclarecimentos a respeito das regras, de como jogar e acerca do ambiente e dos objetivos de aprendizagem pretendidos, entre outros objetivos. Necessário ainda, após o jogo, fazer um debriefing, a fim de auxiliar os estudantes na revisão de eventos e no desenvolvimento de pensamento crítico-reflexivo para os pontos positivos e negativos das ações por eles realizadas durante o jogo, bem como para correção de eventuais equívocos e reflexão para a prática clínica. ${ }^{(24,25)}$ O tempo utilizado no debriefing depende das situações propostas nos cenários de simulação e dos objetivos desta atividade, não devendo exceder em três vezes o tempo de jogo. ${ }^{(26,27)}$

Outra ferramenta utilizada foi o chat educativo, acontece num curto período de tempo, sendo importante para aprender a raciocinar agilmente e sintetizar o conhecimento, estimular a construção de conhecimento e vínculo entre os estudantes. ${ }^{(28)}$

O fórum também auxiliou no desenvolvimento da disciplina (Figura 4), por estimular a construção conjunta dos alunos, além de auxiliar na aprendizagem da comunicação, escrita mais crítica e reflexiva. ${ }^{(28)}$

E-Books também compuseram o material de apoio à disciplina on-line, um foi fonte de sensibilização do módulo Estratégias Lúdicas de Comunicação com a Criança; outro, um capítulo de livro virtual, desenvolvido pela EERP-USP, auxiliou no preparo de estudantes para um chats (Figuras 5 e 6).

Os infográficos (Figura 7), embora não tenham sido diretamente explorados, foram disponibilizados no e-disciplinas como material de apoio. Diferentes autores têm considerado a relevância deste material, pois suas imagens e textos em movimento conseguem reter a atenção do usuário, suas animações tornam mais confortável o contato com as informações, auxiliam na aprendizagem de situações de difícil compreensão, facilitam a visualização e o entendimento acerca de processos e procedimentos, bem como reduzem o esforço cognitivo para o processamento da informação e motivam o aprendizado. ${ }^{(29,30)}$

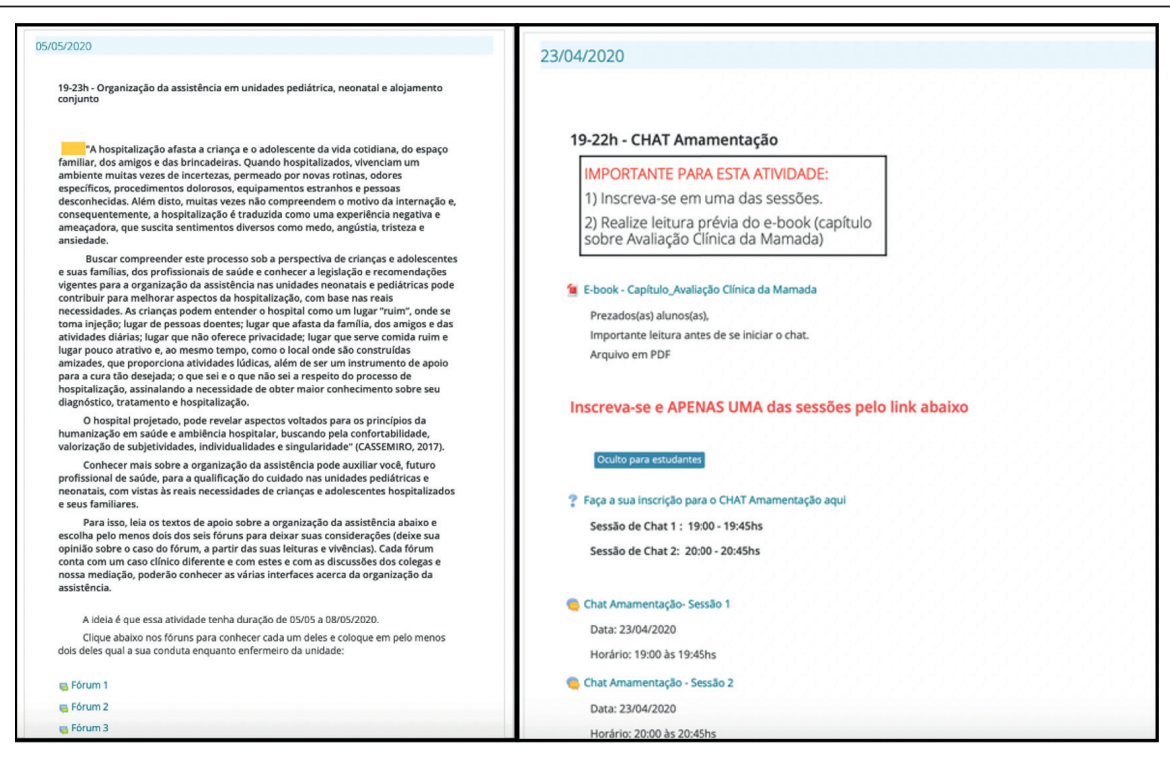

Figura 4. À esquerda, a tela do fórum e, à direita, a tela de um dos chats educacionais 


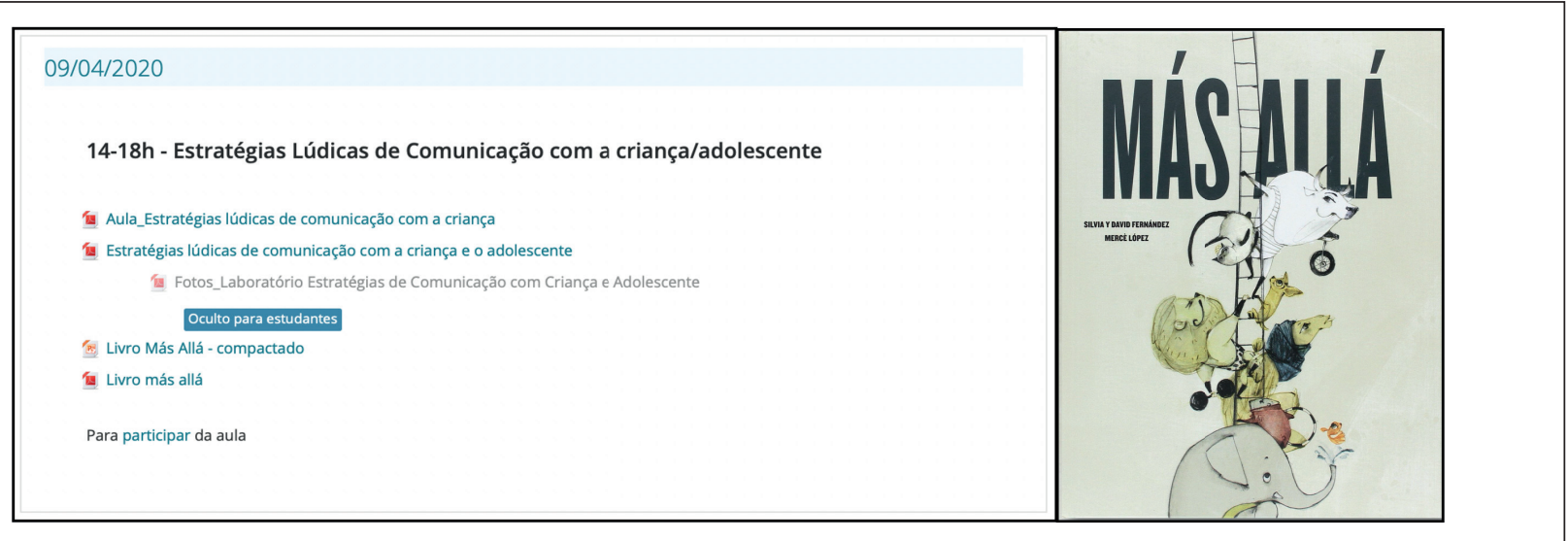

Figura 5. À esquerda, tela do módulo Estratégias Lúdicas de Comunicação com a Criança e o Adolescente e, à direita, e-Book Más Allá

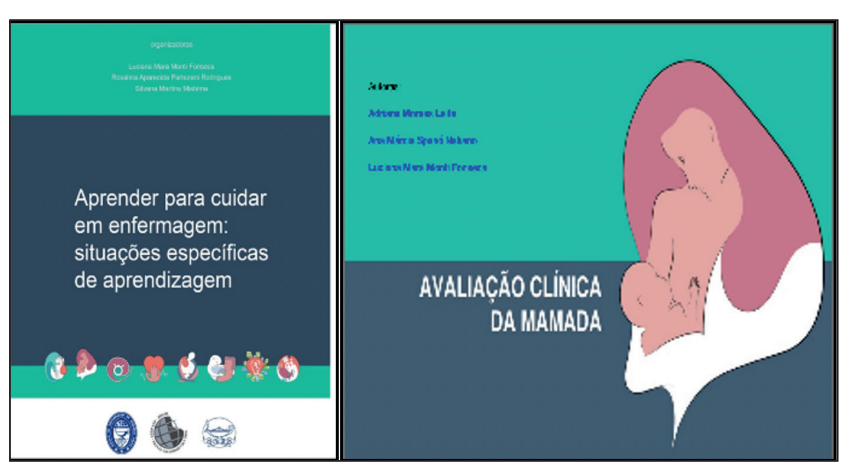

Figura 6. À esquerda, e-Book produzido pela EERP-USP e, à direita, o capítulo utilizado no chat educacional

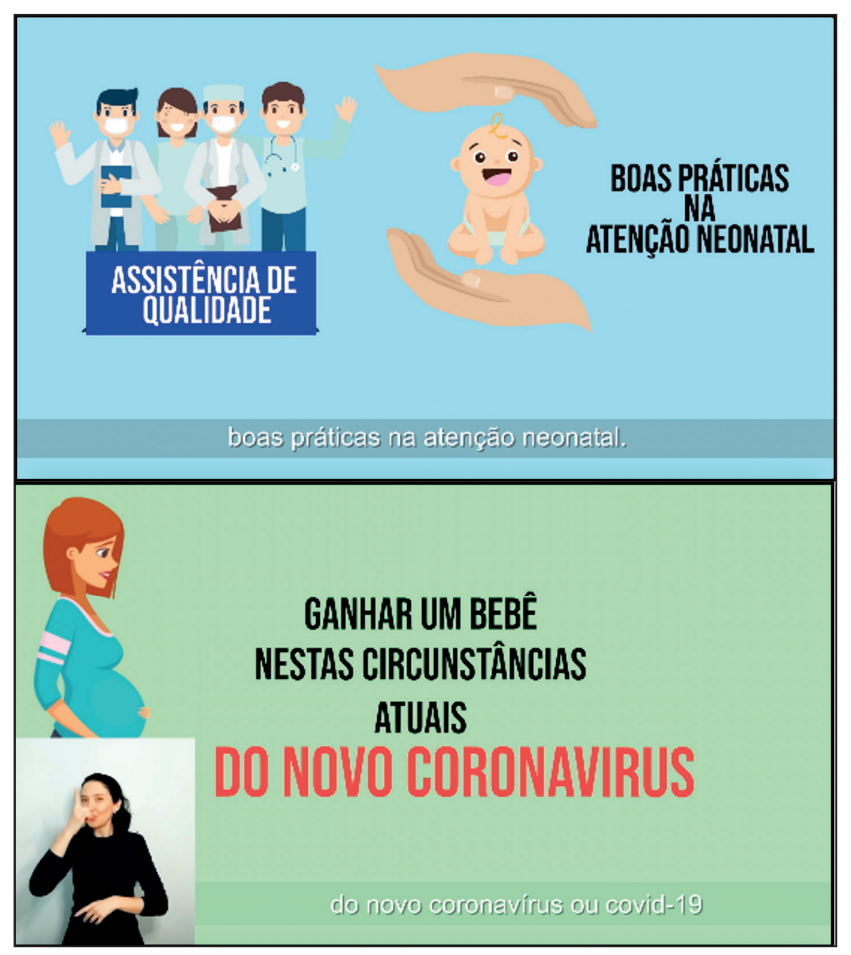

Figura 7. Infográficos disponibilizados na disciplina como material de apoio

\section{Construção da disciplina na plataforma e-Disciplinas}

A disciplina e seu conteúdo na plataforma e-Disciplinas foram construídos pelos próprios docentes da área com apoio técnico de uma equipe da unidade de Ensino. O material pode ser acessado no seguinte endereço: https://edisciplinas.usp.br/acessar/.

Para melhor organização do ambiente virtual, foram criados 13 diferentes módulos, em ordem cronológica com datas e respectivas cargas horárias, geralmente de quatro horas, já contadas as atividades realizadas anteriormente ao encontro não presencial, o encontro em si e as atividades pós-encontro. Ao final, foram disponibilizados mais dois módulos: um de avaliação (da disciplina, dos docentes e de atividades específicas como os laboratórios) e outro com links interessantes acerca da saúde da criança e do adolescente hospitalizado, como um "Saiba mais".

Cada módulo foi desenvolvido seguindo a mesma ordem: primeiro o PDF com os slides do conteúdo, abaixo as ferramentas e os multimeios de apoio e, ao final, o link para o encontro não presencial. Após a realização de cada encontro remoto, postava-se sua respectiva gravação, com a devida permissão dos estudantes e do professor, bem como a tarefa a ser feita pelo aluno.

O ambiente virtual de aprendizagem objetiva a dinamização, colaboração, interação e contextualização da disciplina para que o processo ensino-aprendizagem ocorra. Os nativos digitais são naturalmente ativos e dinâmicos, pois já nasceram utilizando as diferentes mídias digitais e, cotidianamente, modificam, 


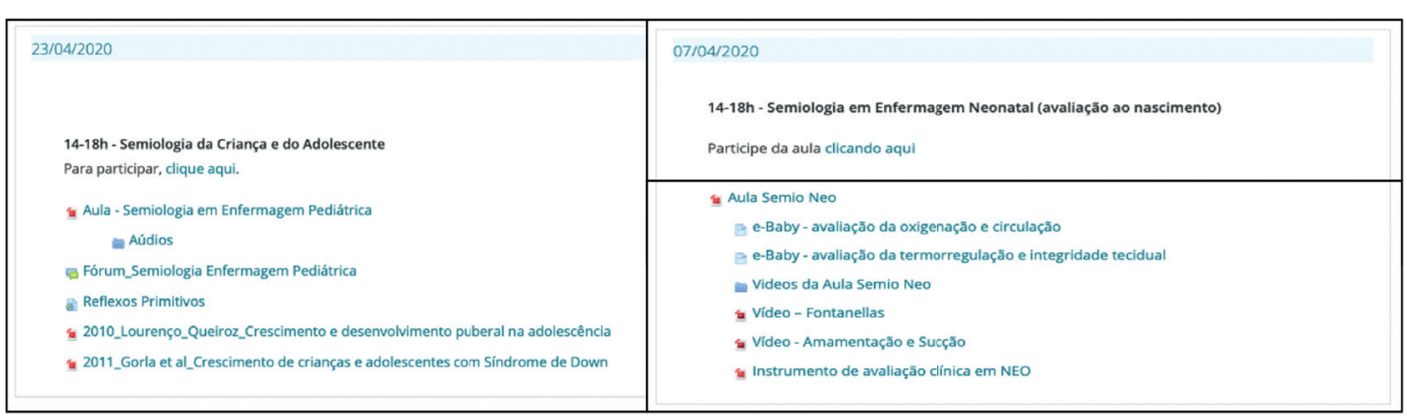

Figura 8. À esquerda, tela do módulo Semiologia da Criança e do Adolescente e, à direita, tela do módulo Semiologia Neonatal

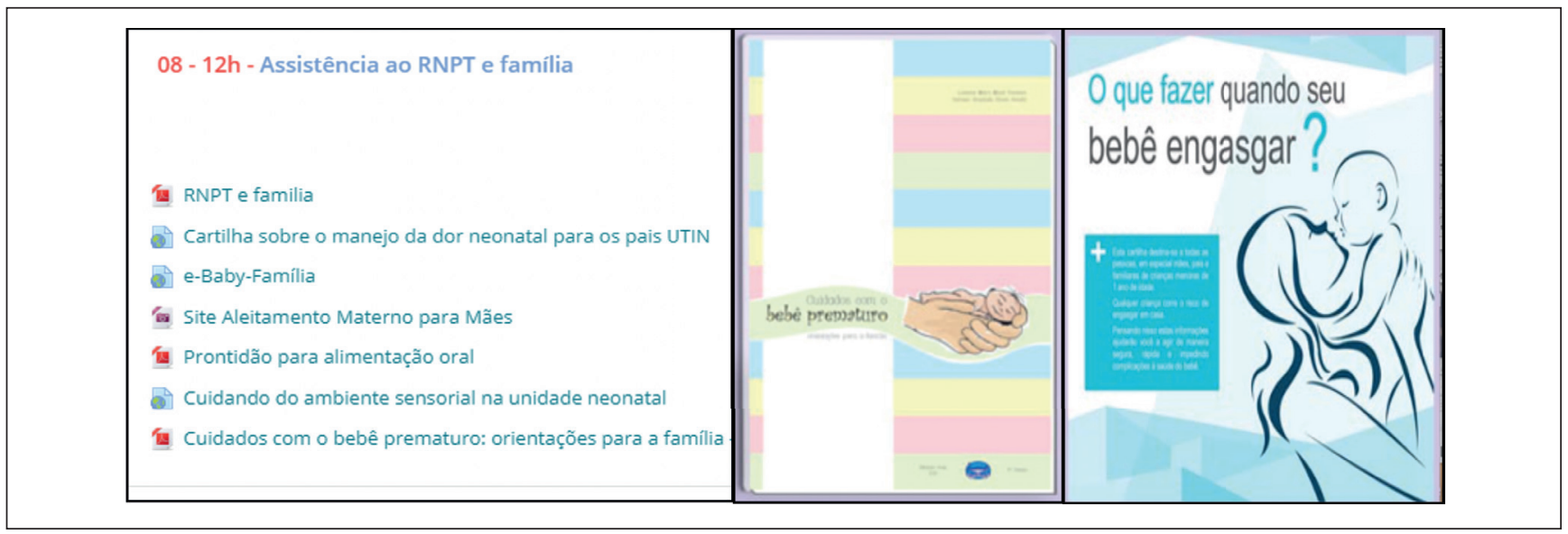

Figura 9. À esquerda, tela do módulo Assistência ao Pré-Termo e Família; no centro e à direita, cartilhas educativas utilizadas durante as atividades práticas no hospital

produzem, compartilham e divulgam amplamente suas ações nas redes sociais. Assim, o professor que lida com este perfil de aluno não deve estar centralizado na comunicação, tampouco apresentar-se como detentor do conhecimento e manter o aluno como mero aprendiz, com pouca ou nenhuma participação neste processo. O professor precisa intermediar o conhecimento, incentivando e organizando atividades de aprendizagem auxiliado por tecnologias digitais e indicando os caminhos adequados a uma aprendizagem conjunta (Figuras 8 e 9).

Neste contexto, e para este público especialmente, o professor precisa utilizar multimeios: imagens dinâmicas (vídeos e animações) e estáticas (fotos e desenhos), áudios, textos, hipertextos, gráficos, blogs, wikis, portfólios, dentre outros. São instrumentos que favorecem a aprendizagem e estimulam a corresponsabilização do aluno pela construção de seu conhecimento, tornando-o mais autônomo. ${ }^{(14)}$

\section{Aplicação das atividades teóricas e da avaliação on-line da disciplina}

A disciplina ERM0309 - Cuidado Integral à Saúde da Criança e do Adolescente foi apresentada aos estudantes assim que disponibilizado o agendamento no Google meet ${ }^{\circledR}$. Teve início com uma breve apresentação dos professores e, em seguida, compartilhou-se na tela o planejamento das aulas, para que fosse visualizado por todos os estudantes na plataforma e-Disciplinas. No momento seguinte, foram fornecidas orientações gerais, apresentado o ambiente virtual e promovidas discussões sobre as atividades nas semanas seguintes, de modo que a construção do contrato didático ocorreu conjuntamente. Nesta ocasião, eles também foram estimulados a analisar como se sentiam diante da pandemia, sobretudo frente à necessidade de distanciamento social, das dificuldades e 
facilidades encontradas para uso da tecnologia e da internet e da presença ou ausência da família. Para estimular o diálogo, foi aberto ainda um canal de conversa entre professor-estudante no aplicativo Whats $A p p^{\circledR}$.

O contrato didático previa, entre outros pontos, que os alunos realizassem algumas atividades antes do encontro síncrono, tais como leitura dos textos de apoio, da aula em PDF e dos materiais/ferramentas. Alguns módulos incluíam ainda atividades pós-encontro, que deveriam ser realizadas e enviadas ao professor, características da aula invertida, que foram adaptadas para disciplina.

O estudante pode verificar seu próprio desempenho por meio de testes e atividades durante ou após a aula. Este feedback que pode ser dado pelo sistema, pelo professor ou mediante a observação das respostas de seus colegas. ${ }^{(31)}$ Estudo $^{(31)}$ corrobora essa afirmativa e recomenda que os professores ofereçam atividades on-line e o off-line que se conectem e complementem, pois isso possibilita diferentes formas de proporcionar a aprendizagem de uma mesma temática.

Na aula invertida, há passos que antecedem a aula em si, os professores preparam os conteúdos, compartilha-os com os alunos e planejam as atividades. Durante a aula, o conteúdo é discutido e problematizado e, após, alunos e professor têm a possibilidade de avaliar o ensino-aprendizagem. ${ }^{(31)}$

Evidências atuais sugerem que aula invertida no ensino das profissões da saúde produz uma melhora significativa no aprendizado dos alunos em comparação com os métodos de ensino tradicionais (diferença média padronizada, $\mathrm{SMD}=0,33$, intervalo de confiança de $95 \%$, IC $=0,21-0,46, p<0,001)$. Além disso, mostrou-se ainda mais eficaz quando usados testes no início de cada sessão em sala de aula. ${ }^{(32,33)}$

Em cada um dos módulos, procurou-se não ultrapassar a carga horária total de quatro horas, somando-se as atividades pré-encontro, o encontro não presencial e o pós-encontro. Especificamente os encontros não presenciais não ultrapassaram mais do que $90 \mathrm{mi}$ nutos, pois ${ }^{(3)}$ algumas características dos nativos digitais são a rapidez em consumir informações e o pouco tempo de atenção em cada atividade.

O processo de aprendizagem dos nativos digitais pode ser favorecido, na medida que é sentido por eles pela diversidade de instrumentos e atividades avaliativas, pela individualização do ensino, pelo feedback imediato, pela motivação à autoavaliação e pela interação afetiva e social as quais podem ser favorecidas pelas tecnologias digitais. ${ }^{(34)}$

A aprendizagem afetiva e social refere-se a algumas capacidades dos alunos: de se associarem aos colegas, interagirem e usarem recursos compartilhados para realizar tarefas de aprendizado; de se projetarem social e emocionalmente no grupo; e de estabelecerem uma conexão social e desenvolverem o sentimento de pertencimento à turma.

No contexto de aprendizagens em ambientes virtuais, as capacidades social e afetiva caracterizam-se pela relação entre os recursos, os sujeitos e as atividades, os quais não se restringem à um conjunto de ferramentas, mas em um ambiente relacional onde sujeitos e objetos técnicos interagem e influenciam-se mutuamente ao longo do processo de ensino e aprendizagem. ${ }^{(35)}$

Dessa forma, durante a disciplina, a atenção esteve voltada a cada gesto, colocação e participação individual, ou seja, cada momento vivido pelo aluno foi considerado na avaliação formativa do processo de ensino-aprendizagem. Outro instrumento de avaliação foi a avaliação cognitiva, também realizada remotamente e auxiliada pelo Google Forms ${ }^{\circledast}$. Além disso, buscou-se integrar a esta avaliação tecnologias digitais e multimeios em suas questões, na tentativa de atender às expectativas dos estudantes nativos digitais, que consomem tecnologias diariamente, em todos os setores de suas vidas.

Estudos mostram que a avaliação acontece ao longo de cada intervenção feita pelos estudantes na aula on-line, bem como durante suas participações nas atividades e nas trocas que estabelecem com o professor. No decorrer da formação, o professor vai conhecendo os estudantes e percebendo, em detalhes, seus progressos e desempenhos. Para além desta avaliação formativa, pode-se utilizar a avaliação somativa. ${ }^{(36)}$

O feedback, ou seja, a devolutiva da aprendizagem dos estudantes, é necessário para identificar onde eles estão, onde precisam chegar e de que forma. Trata-se de um caminho para avaliar a aprendizagem. ${ }^{(37)}$

\section{Desafios encontrados no ensino remoto}

As características do ensino remoto emergencial impedem a replicação do modelo presencial e vice-versa. 
Não se trata, também, do ensino a distância, nos moldes em que é conhecido.

Não cabe, no ensino remoto, o uso de tecnologias digitais educacionais por modismo, deslumbramento, nem com vistas a uma prática meramente instrumental. Essas tecnologias precisam ser pensadas e selecionadas com base nos reais objetivos de aprendizagem, no método de ensino escolhido e nas condições heterogêneas da população-alvo, ou seja, os estudantes, para acessá-las. Devem ainda ser utilizadas como meios e não fim, mediadas por metodologias ativas de aprendizagem, e estarem em consonância com o Projeto Pedagógico do Curso.

Uma efetiva aprendizagem não é apenas cognitiva, mas também afetiva e social, o que evidencia a necessidade de estimular entre os alunos a motivação, colaboração, cooperação e emancipação, bem como o trabalho em rede, por meio de diferentes experiências de aprendizagem.

Assim, a capacitação pedagógica do docente se faz urgente. Há também a necessidade de repensar atividades para a formação dos professores acerca dos processos de avaliação da aprendizagem por meio das tecnologias digitais. ${ }^{(38)}$ Contudo, deve-se reconhecer que eles tiveram muito pouco tempo para migrar para o ensino digital em virtude da pandemia da COVID-19, de modo que o planejamento da disciplina aqui apresentado foi emergencial e realizado da melhor forma e na medida do possível. Favoreceu este processo a experiência de alguns docentes que já tinham como objeto de estudo as tecnologias educacionais proativas e inovadoras e estavam gradativamente implementando estratégias não presenciais como apoio do ensino presencial. Esse conhecimento prévio foi fundamental, pois incentivou e auxiliou os demais professores a também incluírem, em seus módulos, recursos digitais.

Outro desafio identificado pelos alunos foi a precariedade de acesso à internet e ao hardware. Foi notória também a disponibilidade de poucos equipamentos para uso compartilhado da família, visto que diversas pessoas estavam confinadas na mesma casa, trabalhando ou realizando atividades escolares simultaneamente. Em alguns casos, havia um único computador ou dispositivo móvel para todos.

Por fim, um último desafio inclui a necessidade de planejar a continuidade da disciplina, que é clínica e requer atividades prática nos laboratórios de si- mulação e nas unidades hospitalares para assistência ao paciente real, neste momento, em que a curva da pandemia ainda é ascendente, não se sabendo ao certo quando a situação estará sob controle.

No pós-pandemia, vislumbra-se que o uso de tecnologias digitais será mais natural, inclusive com possibilidades de um ensino híbrido, aspecto favorável a estudantes nascidos na era digital.

Pensar em uma educação híbrida pressupõe o reconhecimento de que não há uma única forma de ensinar e aprender. As tecnologias digitais e o trabalho colaborativo podem caminhar juntos e propiciar momentos de aprendizagem e trocas que transcendem as barreiras físicas de uma sala de aula. ${ }^{(17)}$

\section{Considerações finais}

A opção de abrir canais para uma escuta sensível dos estudantes a respeito da pandemia e dos impactos por ela causados na vida de cada um partiu do reconhecimento de que a aprendizagem não é apenas cognitiva, mas também social e afetiva. Assim, antes de cada encontro não presencial, eles puderam se expressar e contar como se sentiam neste momento, sendo ainda incentivados a falar sobre o encontro anterior e a refletir sobre os conteúdos abordados. Essas discussões foram importantes durante todo o processo, pois permitiram identificar a necessidade de revisar alguns conteúdos, ferramentas, métodos, plataformas e o papel dos professores, além da autoavaliação dos alunos. No ensino remoto, professores e estudantes, conjuntamente, apreenderam alguns aspectos relevantes, tais localização do professor na "sala de aula" virtual, imagem na tela (professor e estudantes), mediação das discussões na perspectiva relatada pelos professores como sair do lugar comum - "frente da sala" e ir para o "lado a lado". Apreenderam também o potencial de intervenções individuais e em grupos para auxiliar na construção conjunta do conhecimento e incentivar a proatividade no processo ensino-aprendizagem, com vistas a uma participação mais ativa do sujeito que aprende.

\section{Referências}

1. Car J, Carlstedt-Duke J, Tudor Car L, Posadzki P, Whiting P, Zary N, et al. Digital Education in Health Professions: The Need for Overarching Evidence Synthesis. J Med Internet Res. 2019;21(2):e12913. 
2. Fonseca LM, Leite AM, de Mello DF, Silva MA, de Lima RA, Scochi CG. Tecnologia educacional em saúde: contribuições para a enfermagem pediátrica e neonatal. Esc Anna Nery. 2011;15(1):190-6.

3. Prensky M. Digital natives, digital immigrants. On the Horizon. 2001;9(5):2-6.

4. Prensky M. From digital natives to digital wisdom: hopeful essays for 21st Century learning. California: Corwin Press; 2012. 240 p.

5. Chen Y, Guo Y, Pan Y, Zhao ZJ. Structure analysis of the receptor binding of 2019-nCoV. Biochem Biophys Res Commun. 2020;525(1):135-40.

6. Kupferschmidt K, Cohen J. Can China's COVID-19 strategy work elsewhere? Science. 2020;367(6482):1061-2.

7. World Health Organization (WHO). Statement on the second meeting of the International Health Regulations (2005) Emergency Committee regarding the outbreak of novel coronavirus (2019-nCoV) Genève:WH0; 2020 [cited 2020 Sep 29].Available from: https:// www.who.int/news-room/detail/30-01-2020-statement-on-the-second-meeting-of-theinternational-health-regulations-(2005)-emergency-committee-regarding-the-outbreakof-novel-coronavirus-(2019-ncov)

8. Aquino EM, Silveira IH, Pescarini JM, Aquino R, de Souza-Filho JA, Rocha A S, et al. Social distancing measures to control the COVID-19 pandemic: potential impacts and challenges in Brazil. Cien Saude Colet. 2020;25 (Suppl 1):2423-46.

9. Costa R, Lino MM, de Souza Al, Lorenzini E, Fernandes GC, Brehmer LC F, et al. Nursing Teaching in COVID-19 Times: how to reinvent it in this context? Texto Contexto Enferm. 2020;29e20200202.

10. Moran J. Metodologias ativas para uma aprendizagem mais profunda, In BACICH\& MORAN (Orgs). Metodologias ativas para uma educação inovadora. Porto Alegre: Penso, 2018. p. 2

11. Bacich L, Moran J. Metodologias ativas para uma educação inovadora: uma abordagem teórico-prática. Porto Alegre: Penso; 2018. 260 p.

12. Silva ID, Prates T S, Ribeiro LF. New technologies and learning: challenges faced by the teacher in the classroom. Revista em Debate (Florianópolis). 2016; 16: 107-23.

13. Bortolazzo SF. Nascidos na era digital: outros sujeitos, outra geração. In: XVI ENDIPE Encontro Nacional de Didática e Práticas de Ensino. Campinas; 2012. p. 11 [citado 2020 Set 15]. Disponivel em: https://www.univille.edu.br/community/novoportal/VirtualDisk. html?action=readFile\&file=Nascidos_na_era_digital_outros_sujeitos_outra_geracao_ Bortolazzo_2012.pdf\&current=/AI/CIP/Estilos_de_aprendizagem_e_geracao_internet

14. Pereira AS, Parreira FJ, Silveira SR, Bertagnolli SC. Metodologia da aprendizagem em EAD. Santa Maria: UFSM; 2017.

15. Holanda VR, Pinheiro AK, Holanda ER, Santos MC. Teaching and learning in a virtual environment: nursing students' attitude. REME Rev Min Enferm. 2015;19(1):141-7.

16. Reiter GG, Reiter GM. A utilização de multimeios como ferramentas de otimização dos conhecimentos no ensino jurídico. Rev Extensão Foco. 2017;5(1):34-44.

17. Bacich L, Moran J. Aprender e ensinar com foco na educação híbrida. Pátio. 2015;(25):457.

18. Pereira J, Janhke G. A produção de vídeo nas escolas: educar com prazer. Pelotas (RS): ErdFilmes; 2012.

19. Hellman AN, Cass C, Cathey H, Smith SL, Hurley S. Understanding Poverty: Teaching Social Justice in Undergraduate Nursing Education. J Forensic Nurs. 2018;14(1):11-7.
20. Meska MH, Mano LY, Silva JP, Pereira GA Junior, Mazzo A. Emotional recognition for simulated clinical environment using unpleasant odors: quasi-experimental study. Rev Lat Am Enfermagem. 2020;28:e3248.

21. Roediger HL 3rd, Putnam AL, Smith MA. Ten benefits of testing and their applications to educational practice. Psychol Learn Motiv. 2011;5:1-36.

22. Dias JD, Domingues AN, Tibes CM, Zem-Mascarenhas SH, Fonseca LM. Serious games as an educational strategy to control childhood obesity: a systematic literature review. Rev Lat Am Enfermagem. 2018 2018;26:e3036.

23. Westera W. Why and how serious games can become far more effective: accommodating productive learning experiences, learner motivation and the monitoring of learning gains. Educ Technol Soc. 2019;22(1):59-69.

24. D'Agostini MM, Aredes ND, Campbell SH, Fonseca LM. Serious Game e-Baby Família: an educational technology for premature infant care. Rev Bras Enferm. 2020;73(4):1-8.

25. INACSL Standards Committee. INACSL standards of best practice: simulation design. Clin Simul Nurs. 2016;12(1):S5-12.

26. INACSLStandards Committee. INACSL Standards of Best Practice: SimulationSM SimulationEnhanced Interprofessional Education (Sim-IPE). Clin Simul Nurs. 2016;12:S34-8.

27. Fonseca LM, Monteiro JC, Aredes ND, Bueno JV, Domingues AN, Coutinho VR, et al. Interdisciplinary simulation scenario in nursing education: humanized childbirth and birth. Rev Lat Am Enfermagem. 2020;28:e3286.

28. De Lima LG, Haguenauer CJ. Perspectiva dos alunos de um curso superior sobre 0 uso das ferramentas e-mail, chat e fórum em um ambiente virtual de aprendizagem. Rev IberoAmericana Estud Educ. 2015;10(1):83-97.

29. Dorneles LL, Martins VD, Morelato CS, De Goes FD, Fonseca LM, De Camargo RA. Development of an animated infographic on Permanent Health Education. Rev Lat Am Enfermagem. 2020;28:e3311.

30. Scott H, Fawkner S, Oliver C, Murray A. Why healthcare professionals should know a little about infographics. Br J Sports Med. 2016;50(18):1104-5.

31. Trevisani F M. Ensino híbrido, o que é e como utilizá-lo? Blog do Sílabe. 2019 [citado 2019 Ago 15]. Disponivel em: https://silabe.com.br/blog/ensino-hibrido-o-que-e/

32. Schmitz EX, Reis SC. Sala de aula invertida: investigação sobre o grau de familiaridade conceitual teórico-prático dos docentes da universidade. ETD - Educ Temática Digit. 2018;15;20(1):153.

33. Hew KF, Lo CK. Flipped classroom improves student learning in health professions education: a meta-analysis. BMC Med Educ. 2018;18(1):38.

34. Fernandes D. Para uma teoria da avaliação no domínio das aprendizagens. Est Aval Educ. 2008;19(41):347-72.

35. Santos E, Silva M. Desenho didático interativo na educação online. Rev Iberoam Educ. 2009;(49):267-87.

36. Pérez GB, Sáiz FB. Miravalles AF i. Didáctica universitaria en entornos virtuales de enseñanza-aprendizaje. 3rd ed. Madrid: Narcea Ediciones; 2016. 250 p.

37. Fernandes D. Avaliar para aprender: fundamentos e práticas (minicurso). Congresso Nacional de Formação de Professores CNFP, 4, 35. Águas de Lindóia: UNESP; 2018.

38. Couto De Oliveira M, Scherer S. Avaliação formativa em uma disciplina a distância e a integração de tecnologias digitais nas regulações de aprendizagem matemática. Educ Matemática Rev. 2017;56:304-18. 